\title{
Growth Cones of Chick Sympathetic Preganglionic Neurons in vitro Interact with Other Neurons in a Cell-Specific Manner
}

\author{
Stephen J. Moorman and Richard I. Hume \\ Department of Biology, The University of Michigan, Ann Arbor, Michigan 48109
}

\begin{abstract}
The ability of the growth cones of sympathetic preganglionic neurons to recognize the neurons they encounter during their outgrowth and to react to them in a cell-type-specific manner may play a role in guiding them to appropriate targets during development in vivo. In this study, we examined the in vitro growth of sympathetic preganglionic neurons as they interacted with motor neurons, dorsal root ganglion neurons, and sympathetic ganglion neurons. All of these cell types might potentially be encountered by a growing preganglionic axon. The interaction of sympathetic preganglionic growth cones with each cell type was distinct. Sympathetic preganglionic growth cones fasciculated on motor-neuron neurites, collapsed after contact with the cell bodies and neurites of dorsal root ganglion neurons, and grew across the cell bodies and neurites of sympathetic ganglion neurons. These cell-type-specific responses stand in contrast to the collapse and retraction reported to be the most common growthcone behaviors that result from contact between central and peripheral neurons in vitro and suggest that contact-mediated recognition might be sufficient for growth to and interaction with appropriate targets.
\end{abstract}

Studies in several developing systems have demonstrated that the interactions between active growth cones and particular cells along their pathway can play a critical role in guiding axons to their target. The most detailed studies of cellular interactions between growing axons and cells along their path have been made in insect larvae (for a review, see Bastiani et al., 1985), but a study of similar elegance has recently been made for one class of neurons in a simple vertebrate CNS (Kuwada, 1986). These studies have emphasized contact-directed growth and specific fasciculation, but recent studies have demonstrated that growth cones can show cell-specific avoidance (Kapfhammer et al., 1986; Kapthammer and Raper, 1987a, b). In higher vertebrates, the number of cell types a growing axon in the CNS might encounter is large, which greatly complicates such studies. In contrast, only a limited number of cell types are present in the region where sympathetic preganglionic neurons make an important choice during their growth. During development, these preganglionic neurons, like motor neurons, send their axons from the spinal cord to the periphery through the ventral roots.

\footnotetext{
Received Mar. 8, 1990; revised May 4, 1990; accepted May 10, 1990.

We thank Nancy Hall and Patricia Bach for expert technical assistance in the laboratory, David Bay for photography, and Dr. James Walker for comments on the manuscript. This work was supported by Grant NS-21043.

Correspondence should be addressed to Richard I. Hume, Department of $\mathrm{Bi}$ ology, Natural Science Building, The University of Michigan, Ann Arbor, MI 48109

Copyright (C) 1990 Society for Neuroscience $0270-6474 / 90 / 093158-06 \$ 03.00 / 0$
}

However, at about the point that dorsal root ganglion axons converge on the ventral root to form the mixed spinal nerve, the preganglionic axons turn ventrally to enter the sympathetic chain, rather than continuing in the mixed nerve.

The goal of this study was to characterize the way that growth of preganglionic axons is changed by contact with cells of defined types. All of the cell types that were examined might normally be encountered by a growing preganglionic axon in vivo. In particular, we examined the interaction of preganglionic neurons with motor neurons (MNs), dorsal root ganglia (DRG) neurons, and sympathetic neurons. The results of Kapfhammer and Raper $(1987 \mathrm{a}, \mathrm{b})$ suggested one possible outcome of these experiments. Based on in vitro studies of the interaction between neurites of several different types of cells, they suggested that CNS and PNS neurons bear surface markers that serve as distinct "labels." Their basic observation was that when a cell of one type (e.g., CNS) encountered a cell of the other type (PNS), its growth cone collapsed and grew elsewhere. However, if it encountered a cell of the same type, it grew freely across it. Based on this "2-label" hypothesis, the most common growth-cone behavior to expect after contact between preganglionic neurons and DRG or sympathetic neurons is collapse and retraction, because the preganglionic cell is of CNS origin and the sympathetic ganglion (SYM) and DRG cells are of PNS origin. By the same logic, the predicted growth-cone behavior during the preganglionic-MN interaction is crossing, because these cells are both of CNS origin. However, because the combinations of cells previously studied never encounter each other in vivo, many key interactions that contribute to the specificity of growth may have been missing. This is a particularly important point because it is clear that even subtly different parts of the CNS, such as temporal and nasal portions of the retina, can respond to the same cues in very different ways (Walter et al., 1987).

\section{Materials and Methods}

The preganglionic neurons were retrogradely labeled in stage- 30 chick embryos by injecting 1-1'-dioctadecyl-3-3-3'-3'-tetramethylindocarbocyanine perchlorate (DiI) into the SYM and allowing sufficient time for the dye to spread retrogradely before plating the cells (Honig and Hume, 1986). We used stage-30 embryos because the migration of the preganglionic ccll bodies from the ventrolateral aspect of the spinal cord to the column of Terni is almost complete at this time (Levi-Montalcini, 1950; Oppenheim et al., 1982). This migration of the preganglionic cell bodies allows us to distinguish between preganglionic neurons and MNs based on their location in the spinal cord. To avoid the possibility of including DiI-labeled MNs, the medial portion of both sides of the spinal cord (containing the cell bodies of the preganglionic neurons) was dissected free from the lateral portion of the spinal cord (containing the cell bodies of the MNs). The spinal cord tissue containing labeled preganglionic neurons was placed in F12 (Gibco Co.) with 4\% BSA. This spinal cord tissue was then cut into very small pieces to be plated as 
explants in modified tissue-culture dishes (modification and media as described in Honig and Hume, 1986) on a polyornithine/laminin substratum. Dishes were first coated with polyornithine $(0.1 \mathrm{mg} / \mathrm{ml}$ distilled water). After $24 \mathrm{hr}$, the dishes were rinsed with distilled water and allowed to air dry. Prior to coating with laminin (25 $\mu \mathrm{g} / \mathrm{ml}$ PBS), the dishes were sterilized under ultraviolet light. After the laminin solution had covered the dishes for at least $3 \mathrm{hr}$, the solution was replaced by medium containing $5 \%$ heat inactivated horse serum. This medium remained on the dishes until cells were plated.

MNs were retrogradely labeled in stage- 30 embryos by injecting $3,3^{\prime}$-dioctadecyloxacarbocyanine perchlorate $(\mathrm{DiO})$ in the ventral roots. The ventrolateral aspect of the spinal cord with labeled MNs was dissected and prepared for plating as explants in the same manner as the preganglionic explants. The SYMs were removed from stage- $35 \mathrm{em}$ bryos and the DRGs were removed from stage-35-37 embryos. These stages were selected because, at earlier ages, it was difficult to cleanly dissect thoracic SYMs away from the ribs. The DRGs and SYMs were dissociated separately to single cells and then labeled with DiO after dissociation (Honig and Hume, 1986). Before final plating, the cells were preplated for $1 \mathrm{hr}$ in uncoated tissue-culture dishes to reduce the number of non-neuronal cells, then resuspended. We used both thoracic and lumbar ganglia and noticed no difference among them, so all data were combined.

To confirm the observations of Kapfhammer and Raper (1987a, b), the retina was removed from stage-30 chick embryos. A strip of retina from the temporal side of the optic disk was dissected and prepared for plating in a manner similar to the preganglionic explants. To study interactions between retinal ganglion cells and sympathetic cells, dissociated SYM cells were added to the culture dish 24 or $48 \mathrm{hr}$ after the explants were plated, and the dish was returned to the incubator for 1 hr before observations were begun.

To study interactions between preganglionic neurons and MNs explants of both types were plated simultaneously in the same dishes 24 or $48 \mathrm{hr}$ before observations were to be made. To enhance the survival and growth of MNs, the normal medium was supplemented with $50 \%$ muscle-conditioned medium. To study interactions between preganglionic neurons and SYM or DRG neurons, the dissociated SYM or DRG neurons were added to the dishes containing preganglionic explants 24,48 , or $72 \mathrm{hr}$ after the explants were plated. The dishes were then returned to the incubator for $\mathrm{l}$ hr before observations were begun.

Observations were made using a Zeiss IM inverted microscope modified to allow the stage, tissue-culture dish, and objective lenses to be maintained at $37^{\circ} \mathrm{C}\left( \pm 0.1^{\circ} \mathrm{C}\right)$. Video images were acquired using a DageMTI SIT camera, enhanced using a computer digital image processing system (Image-1, Universal Imaging Corp.), and stored on video cassette for analysis using the same computer software. Immediately prior to observation, the tissue-culture dish was completely filled by adding normal media and $20 \mathrm{~mm}$ HEPES (pH, 7.4), and a large coverslip was placed on top to seal the dish and prevent evaporation. Growth cones of specific labeled cell types were identified initially under brief fluorescent illumination, then observed under halogen illumination. Green (Nikon green interference filter 85972) and yellow (Rosco "medium straw" theatrical acetate gel) filters were placed between the halogen light source and the specimen to prevent phototoxicity.

Only the initial interactions between a preganglionic growth cone and a specific cell or cell process were included in the data presented in Table 1 . The coordinates of each growth cone and 2 reference points were recorded from the videotape at 5-min intervals. The growth-cone coordinates were corrected for any change in reference-point coordinates and used to calculate distance grown. Several growth cones were tracked at 1-min intervals to assure that 5-min interval tracking did not introduce any sampling error. The distance grown was plotted versus time, with markers indicating when growth cone-neurite contact occurred. Based on our observations, we divided growth-cone behavior into the following categories: collapse, a resorption of both the lamellipodia and at least a majority, if not all, the filopodia coincident with the cessation of forward growth; fasciculation, a turn to grow for at least $15 \mu \mathrm{m}$ on the process of another cell; grow across, self evident; other, growth-cone behaviors that include characteristics of 2 or more of the other defined behaviors.

\section{Results}

Labeled neurons were identified by brief illumination using the appropriate fluorescence filters. The growth of their neurites was
Table 1. Growth cone behavior after contact

\begin{tabular}{ll} 
Collapsed \\
Interaction & $\begin{array}{l}\text { and/or } \\
\text { retracted Fasciculated Grew across Other }\end{array}$ \\
\hline
\end{tabular}

Preganglionic growth cone contacting neurite or cell body of:

$\begin{array}{lrrrr}\text { DRG } & 20 & 0 & 1 & 0 \\ \text { MN } & 0 & 15 & 3 & 1 \\ \text { SYM } & 0 & 0 & 21 & 0\end{array}$

Type of growth cone contacting preganglionic neurite:

$\begin{array}{lrrrr}\text { DRG } & 7 & 0 & 3 & 0 \\ \text { MN } & 0 & 1 & 10 & 1 \\ \text { SYM } & 10 & 0 & 3 & 0\end{array}$

This table presents a summary of growth-cone behaviors observed. Each value is the number of observations made. When a preganglionic growth cone contacted a sympathetic neurite, the growth cone always grew across the neurite, though it sometimes transiently slowed. More than $3 / 4$ of the preganglionic growth cones that contacted an MN process fasciculated on the process; most of the rest grew across. Almost all the preganglionic growth cones that contacted DRG neurons collapsed. The behaviors of the growth cones of the 3 other cell types after contact with neurites of preganglionic neurons were often not the same as when the growth cone of a preganglionic neuron contacted them.

then followed using phase-contrast microscopy. Identified neurons of all types grew for at least $6 \mathrm{hr}$ under the conditions describcd abovc, with continuous illumination from the halogen lamp, as long as the green and yellow filters were in the light path. The green filter alone was necessary for prolonged neurite outgrowth if the cells were not labeled with any dye. The yellow filter and the green filter were both necessary for continuous growth of cells labeled with DiI. The growth rate of preganglionic neurites from explants averaged $42.7 \pm 0.24 \mu \mathrm{m} / \mathrm{hr}$ (mean \pm SEM). There was no difference between the growth rate of preganglionic neurites from explants and those in dissociated cell culture $(40.7 \pm 0.18 \mu \mathrm{m} / \mathrm{hr})$. In co-cultures, preganglionic neurites were never observed to turn toward or away from any neuronal cell type before any contact had occurred.

Before studying the interactions of preganglionic neurites with other cells, we wanted to verify that our growth conditions were similar to those previously used by others. Observations of retinal growth cones contacting SYM cell processes confirmed the growth-cone behavior previously reported by Kapfhammer and Raper (1987b). In all 5 cases observed, retinal ganglion cell growth cones collapsed after their initial contact with SYM neurons.

The interactions of preganglionic growth cones with DRG neurons were similar to those observed for retinal neurites interacting with SYM cells. In all but 1 case, the preganglionic growth cones collapsed when they encountered a DRG neurite (Table 1, Fig. 1). This collapse behavior did not appear to be related to the angle at which the growth cone approached the DRG cell (range: for collapse $28-90^{\circ}$; for crossing, $76^{\circ}$ ). In the 5 cases where the preganglionic growth cone was observed after it had collapsed and retracted, a growth cone eventually reformed, and when it contacted the same DRG neurite again, it collapsed and retracted. However, only the growth-cone behavior after initial contact was included in the data presented in Table 1.

The behavior of preganglionic neurites when contacting MNs was quite different. In the majority $(79 \%)$ of the interactions where a preganglionic growth cone encountered the neurite of an $\mathrm{MN}$, the preganglionic growth cone turned and grew along the MN neurite (Table 1, Fig. 2). The preganglionic growth cones grew at the about the same rate before $(27.1 \pm 1.2 \mu \mathrm{m} / \mathrm{hr})$ and 


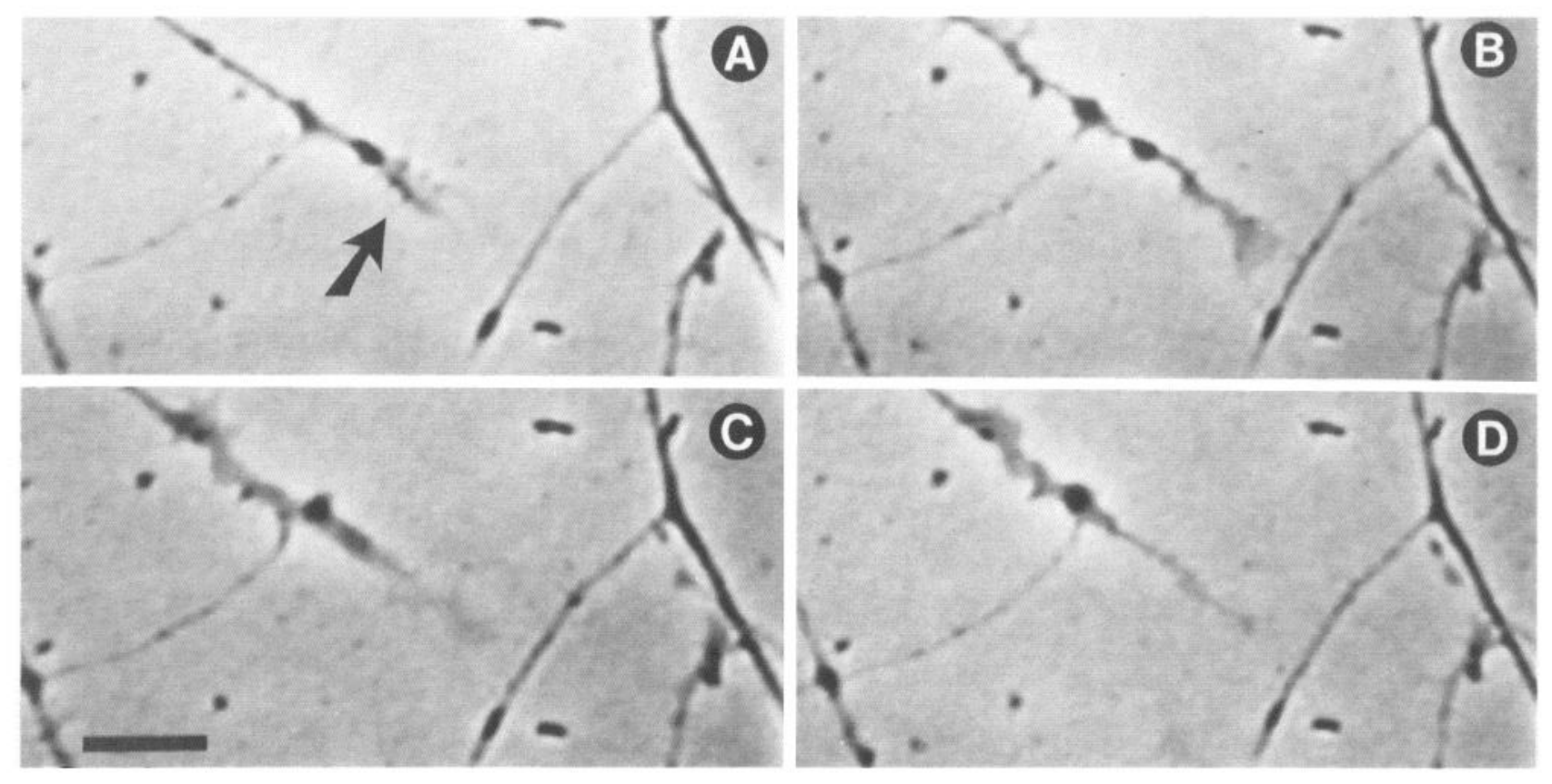

Figure 1. Growth cone of a preganglionic neuron interacting with a DRG neuron. The growth cone (arrow) is shown approaching (A), then contacting $(B)$ a neurite of a DRG cell. Shortly after contact, the growth cone collapsed $(C, D)$. Scale bar, $10 \mu \mathrm{m}$. Elapsed time (in min) after the events in $A: B, 6 ; C, 8 ; D, 10$.

while fasciculating on the MN neurite (30.0 $\pm 0.47 \mu \mathrm{m} / \mathrm{hr})$. It should be noted that the rate of axon outgrowth from preganglionic neurons grown in muscle-conditioned medium was somewhat slower than in normal medium (presumably due to the higher serum concentration). In 3 cases, there was a long delay (1-5 $\mathrm{min}$ ) between the initial contact and when the preganglionic growth cone turned and grew along the $\mathrm{MN}$ neurite, but these contacts were still scored as fasciculation. In a few instances ( 3 of 19), the preganglionic growth cone continued to grow across the MN process without any change in growth rate or morphology. In one case, a preganglionic growth cone crossed an MN neurite at an acute angle, and though the main body of the growth cone continued to grow for approximately $40-50 \mu \mathrm{m}$ past the neurite, filopodial contact with the neurite was maintained. The result was that the growth cone dragged the MN neurite behind it (this interaction was scored as other). This behavior was somewhat similar to the parallel growth of sensory-neuron growth cones after contact with other sensory neurites in vitro observed by Honig and Burden (1989). There was no clear relationship between growth-cone behavior and the angle at which the preganglionic growth cone contacted the $\mathrm{MN}$ process (range: for fasciculation, $26-79^{\circ}$; for crossing, $63-88^{\circ}$ ). However, it is potentially interesting that 2 of the 3 preganglionic growth cones that grew across MN neurites approached the neurite at close to $90^{\circ}\left(87^{\circ}, 88^{\circ}\right)$.

In preganglionic-sympathetic ganglion co-cultures, when preganglionic growth cones encountered the cell bodies and/or processes of SYM neurons, they always crossed them, though the rate of growth often transiently slowed (Table 1, Fig 3). Preganglionic growth cones crossed sympathetic neurites regardless of the angle at which the growth cone contacted the neurite (range, $26-85^{\circ}$ ). In all 3 instances where a preganglionic growth cone contacted a second neurite of a cell it had already contacted, the growth cone did not transiently slow as it did when it contacted the first neurite (Fig. 4). Preganglionic growth cones were never observed to collapse or retract after contact with a SYM neuron.

We also studied a number of interactions where the growth cones of the other 3 cell types contacted neurites of preganglionic neurons. Quite unexpectedly, these reciprocal interactions were not always symmetrical. For instance, preganglionic growth cones typically fasciculated on the neurites of MNs, but MN growth cones typically crossed preganglionic neurites. Furthermore, the reciprocal interactions were not as consistent as the interactions of preganglionic growth cones (Table 1). In general, the reciprocal interactions were consistent with the observations of Kapfhammer and Raper (1987b); the predominant growth-cone behavior after contact with a neurite bearing a label unlike its own (peripheral vs central) was collapse and retraction, while the predominant growth-cone behavior after contact with a neurite bearing a label similar to its own (central vs central) was crossing.

\section{Discussion}

In this study, we examined the in vitro growth of neurites from an identified type of CNS cell, sympathetic preganglionic neurons, as they interacted with 3 different cell types that they might normally encounter in vivo during development. Their interaction with each cell type was distinct. Preganglionic growth cones fasciculated on MN neurites, collapsed after contact with DRG neurons, and grew across SYM neurons. Time-lapse microscopy studies have shown that different neurons from chick embryos can respond in cell-specific ways to the same extracellular matrix molecules (Caroni and Schwab, 1988) and to molecules on the cell surfaces of other neurons (Raper and Kapfhammer, 1990). All these results suggest that neurons respond in a cell-type-specific manner to environmental signals.

After a preganglionic neuron initiates outgrowth in vivo, it sends its axon out a ventral root of the spinal cord. Unfortunately, the details as to which cells a growing preganglionic 

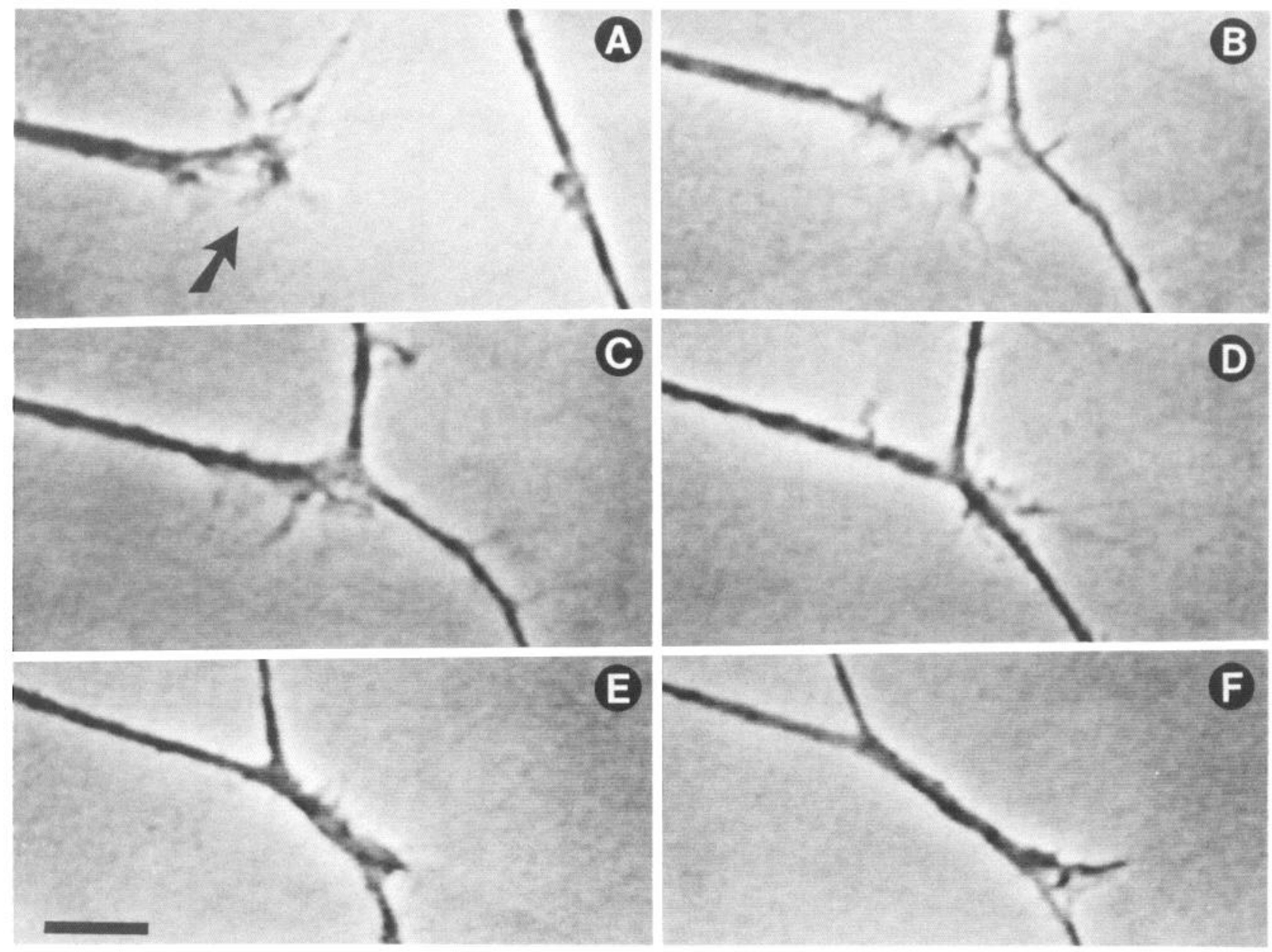

Figure 2. Growth cone of a preganglionic neuron interacting with an $\mathrm{MN}$. The growth cone (arrow) is shown approaching $(A)$, contacting $(B, C)$, and fasciculating $(D-F)$ on the neurite of an $\mathrm{MN}$ in vitro. Scale bar, $10 \mu \mathrm{m}$. Elapsed time (in min) after the events in $A: B, 21 ; C, 22 ; D, 28 ; E, 41$; $F, 80$. The frame was shifted to the right between $A$ and $B$ and between $D$ and $E$ and shifted down between $E$ and $F$.

neuron encounters in the spinal cord and during its growth to the periphery are not known. It is generally thought that, during development, the axons of MNs are the first processes to grow out of the spinal cord and form the ventral root, with preganglionic axons following some time later (Levi-Montalcini, 1950; Yip, 1987). This timing is consistent with the possibility that the preganglionic axons use the $\mathrm{MN}$ axons as guidance cues. We assume that, in vitro, the preganglionic process that leaves an explant is the axon, and we make the same assumption for the MN process that leaves its corresponding explant. Therefore, if the MN axon is used as a pathway in vivo, then it is not unreasonable to expect that the preganglionic growth cone might fasciculate on an MN neurite in vitro. This idea is supported by the observations made in this study. The possibility that the preganglionic growth cones fasciculate on MNs because the MN axon presents a more favorable substratum for growth of preganglionic axons than does the laminin substratum cannot be ruled out. However, if this were the case, one might have expected the preganglionic neurite to grow at a different rate when its growth cone was on an MN axon. This was not the case for the preganglionic growth cones observed in this study.

Once they have exited the spinal cord through the ventral root, the preganglionic axons turn ventrally and leave the ventral root to enter a SYM at or near the point where the DRG axons join the ventral root to become the spinal nerve. This anatomical relationship suggests the possibility that, during development, a preganglionic axon might gain some positional information from DRG axons. For instance, contact with a DRG axon might indicate that the preganglionic growth cone either should turn or has "missed its turn." However, it has previously been demonstrated that specific contact with DRG cells might not be necessary for the preganglionic growth cones to locate the appropriate area of their target. Following removal of the neural crest, including presumptive sympathetic neurons and DRG cells, some of the developing preganglionic cell axons are still able to grow out of the spinal cord to the area that would have been occupied by the sympathetic cells (Yip, 1987). This suggests that the DRG cells do not play an essential role in guiding the preganglionic growth cones. It is possible that the DRG cells serve as one of several guidance cues. Because of redundancy of cues, the deletion of any one cue might not significantly affect the ability of a growth cone to find its appropriate target area. In evaluating the potential role of DRG axons in guiding preganglionic growth cones, it should be noted we confronted Stage30-32 preganglionic neurons with slightly older DRG neurons. The choice of stages was dictated by our need to be able to unequivocally identify the cell types. The details of the in vivo timing of this pathway choice are not known, but for many of 

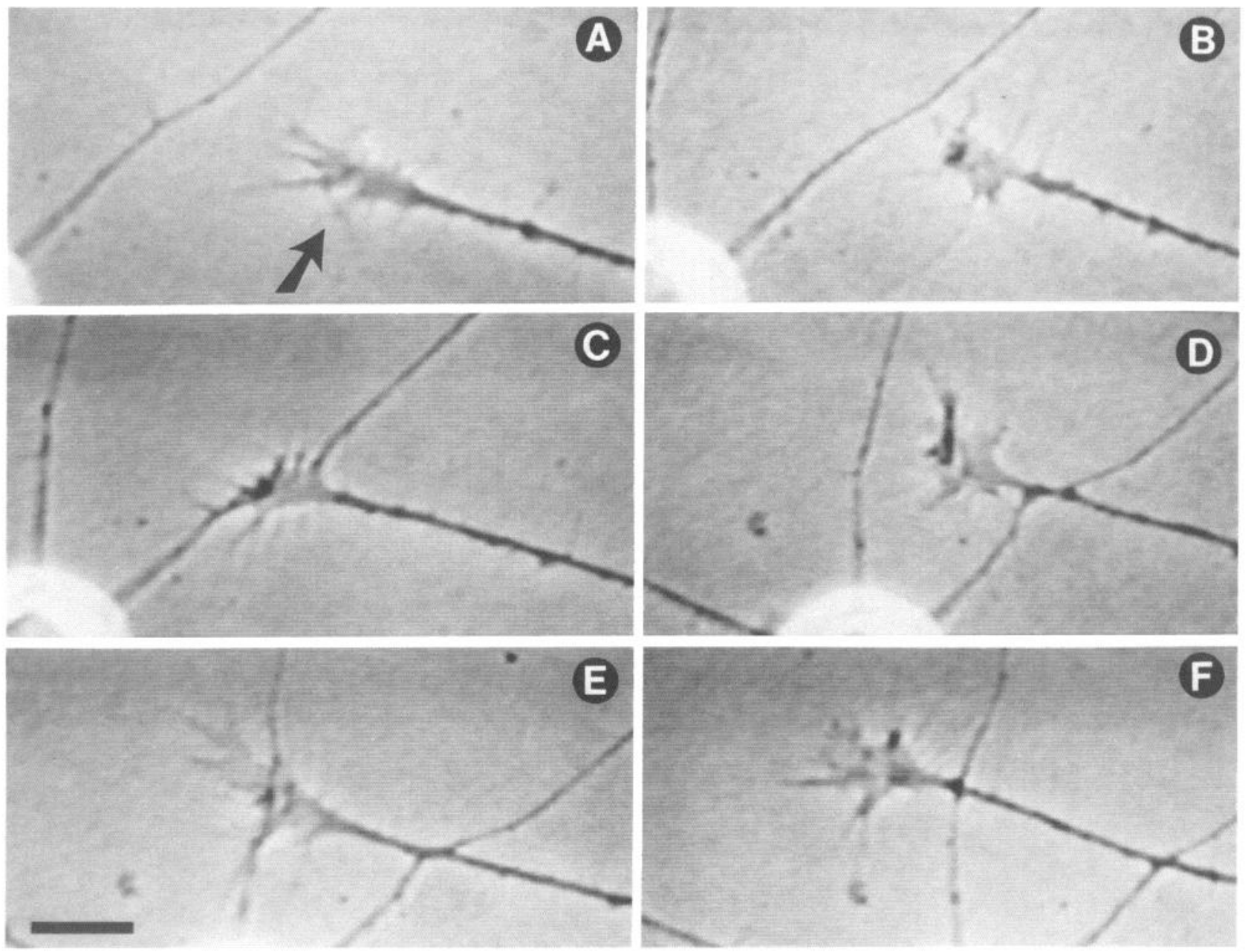

Figure 3. Growth cone of a preganglionic neuron interacting with an SYM neuron. The growth cone (arrow) is shown approaching $(A)$, contacting $(B)$, and growing across 2 neurites of the same SYM cell $(C-F)$. Scale bar, $10 \mu \mathrm{m}$. Elapsed time (in min) after the events in $A: B, 8 ; C, 14 ; D, 27$; $E, 33 ; F, 44$. The frame was shifted to the left between $A-D$ and shifted up between $E$ and $F$.

the preganglionic axons, the decision to leave the ventral root must be made prior to stage 30 , because preganglionic cell bodies can be retrogradely labeled via their projections to the SYMs at this stage (see also Yip, 1987). If the interactions we have studied in vitro are relevant to normal development, then the set of molecules used in this recognition process must be retained on cells for a period of time beyond when they are normally used. It seems that an important next step in evaluating the role of DRG axons in guiding preganglionic growth cones will be to determine the exact anatomical relationship between preganglionic axons and DRG axons during different stages of in vivo development.

Once preganglionic axons have left the ventral root and entered the sympathetic chain, each axon projects to and synapses with many SYM neurons in vivo (Lichtman et al., 1980). Our observation that preganglionic growth cones continued to grow across sympathetic neuron processes, though the growth cones transiently slowed, is consistent with the idea that the preganglionic growth cone is intrinsically capable of recognizing its appropriate target cell type and that it also has the ability to continue its growth in order to synapse with more than one sympathetic cell. We know that, in this culture system, preganglionic neurons can form functional synapses onto ganglion neu- rons, but only at a small proportion of the physical sites of contact (Hume and Honig, 1987).

Kapfhammer and Raper (1987a, b) suggested that at least 2 labels exist on growing axons, one associated with CNS neurons and one associated with PNS neurons. These labels were purported to be involved in a contact inhibition of the growth cone when it encounters a neurite bearing a label unlike its own. Such labels have been postulated to be important in both pathfinding and target recognition. Several groups have recently characterized molecules that may be the signal triggering this contact inhibition (Cox et al., 1990; Davies et al., 1990; Raper and Kapfhammer, 1990). The studies suggesting this 2-label hypothesis were limited in that the tissue types tested would not normally contact each other in vivo. Our observation that when a preganglionic growth cone contacts a DRG neurite in vitro, it collapses and retracts, is consistent with the simple 2-label hypothesis. However, the lack of collapse of preganglionic growth cones after contact with sympathetic neurons argues strongly against the existence of a single "peripheral" label, because sympathetic neurons are of the same embryological origin as DRG cells, and their cell bodies and processes are exclusively peripheral. Furthermore, our results also suggest that target recognition may not require growth-cone collapse, because the preganglionic 


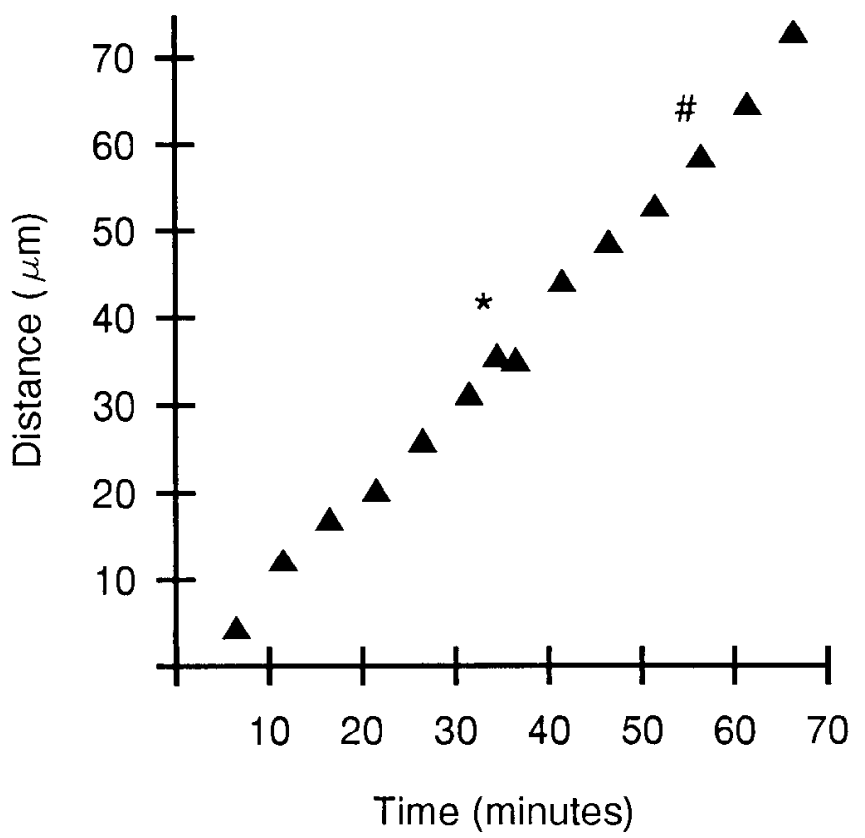

Figure 4. Plot of elongation of preganglionic neurite illustrated in Figure 3. The growth cone is shown as it encountered the 2 processes of the SYM neuron. *, contact with the first neurite; \#, contact with the second neurite. The growth rate transiently slowed after growth-cone contact with the first neurite but not after contact with the second neurite.

neurons commonly interacted with their target SYM cells by transiently slowing, then continuing to grow without any sign of collapse.

The complexity of interaction among growth cones in even a simple system is exemplified by our observations of interactions of the growth cones of the other neuronal cell types with the neurites of preganglionic neurons. We found that 2 pairs of interactions between growth cones and axons were nonsymmetrical: (1) preganglionic growth cones crossed SYM-neuron axons, but SYM-neuron growth cones collapsed after contact with preganglionic axons; and (2) preganglionic growth cones fasciculated on MN axons, but MN growth cones crossed preganglionic axons. One possible explanation of these results is that there is a hierarchy of labels. In the absence of any specific target or pathway cues (as when one observes encounters in vitro between cells that do not normally contact each other), a system of central and peripheral labels would come into play, but during development, these general cues might be superseded by more specific pathway or target cues. In regard to this idea, it is interesting that the 2 interactions that seem almost certain to occur during normal development (preganglionic-MN and preganglionic-SYM neuron) are the ones that are not in accord with the predictions of the 2-label hypothesis. Pcrhaps in these cases, preganglionic growth cones recognize specific labels on the $\mathrm{MN}$ axons and SYM neurons that take precedence over the more general cues. However, at present we have no direct evidence for such a hierarchy.

The failure of $\mathrm{MN}$ growth cones to fasciculate on preganglionic axons has direct implications for the mechanism that allows preganglionic growth cones to fasciculate on motor axons. Clearly, a simple model in which one cell expresses an adhesion molecule over its cell surface and the other expresses a receptor for that molecule cannot apply, because this would produce fasciculation regardless of which neuron initiated the contact.
One possible model that could explain our observations is that the recognition is not based on adhesion. A second is that only a portion of each cell expresses the appropriate adhesive molecules. For instance, if the adhesion molecule were restricted to the growth cone of preganglionic neurons and the receptor restricted to the trailing axon of MN axons, then preganglionic growth cones could recognize and fasciculate on MN axons, but $\mathrm{MN}$ growth cones would grow across preganglionic axons.

In this study, we have examined, in vitro, the growth of neurites from an identified type of CNS cell, sympathetic preganglionic neurons, as they interacted with 3 different cell types that might normally be encountered in vivo during development. Their interaction with each cell type was distinct. The consistent cell-type-specific behaviors of these preganglionic growth cones suggest that contact-mediated recognition might be sufficient for growth to and interaction with appropriate targets. We do not mean to imply that the results presented here are indicative of the only cues, but our observations strongly suggest that not only active avoidance but also active recognition play roles in growth cone navigation in this portion of the developing chick nervous system.

\section{References}

Bastiani MJ, Doc CQ, Helfand S, Goodman CS (1985) Neuronal specificity and growth cone guidance in grasshopper embryos. Trends Neurosci 8:257-266.

Caroni P, Schwab ME (1988) Antibody against myelin-associated inhibitor of neurite growth neutralizes nonpermissive substratum properties of central nervous system white matter. Neuron 1:85-96.

Cox EC, Muller B, Bonhoeffer F (1990) Axonal guidance in the chick visual system: posterior tectal membranes induce collapse of growth cones from the temporal retina. Neuron 4:31-37.

Davies JA, Cook GMW, Stern CD, Keynes RJ (1990) Isolation from chick somites of a glycoprotein fraction that causes collapse of dorsal root ganglion growth cones. Neuron 4:11-20.

Honig MG, Burden SM (1989) Time-lapse studies of encounters between sensory neuron growth cones and neurites. Neurosci Abst 15: 1029.

Honig MG, Hume RI (1986) Fluorescent carbocyanine dyes allow living neurons of identified origin to be studied in long-term cultures. J Cell Biol 103:171-187.

Hume RI, Honig MG (1987) Formation of synapses by sympathetic preganglionic neurons. Neurosci Abst 13:1425.

Kapfhammer JP, Raper JA (1987a) Collapse of growth cone structure on contact with specific neurites in culture. $J$ Neurosci 7:201-212.

Kapfhammer JP, Raper JA (1987b) Interactions between growth cones and neurites growing from different neural tissues in culture. J Neurosci 7:1595-1600.

Kapfhammer JP, Grunewald BE, Raper JA (1986) The selective inhibition of growth cone extension by specific neurites in culture. J Neurosci 6:2527-2534.

Kuwada JY (1986) Cell recognition by neuronal growth cones in a simple vertebrate embryo. Science 233:740-746.

Levi-Montalcini $R$ (1950) The origin and development of the visceral system in the spinal cord of the chick embryo. J Morphol 86:253283.

Lichtman JW, Purves D, Yip JW (1980) Innervation of sympathetic neurones in the guinea-pig thoracic chain. J Physiol (Lond) 298:285299.

Oppenheim RW, Maderdrut JL, Wells DJ (1982) Cell death of motoneurons in the chick embryo spinal cord. VI. Reduction of naturally occurring cell death in the thoracolumbar column of Terni by nerve growth factor. J Comp Neurol 210:174-189.

Raper JA, Kapfhammer JP (1990) The enrichment of a neuronal growth cone collapsing activity from embryonic chick brain. Neuron $4: 21-29$.

Walter J, Henke-Fahle S, Bonhoeffer F (1987) Avoidance of posterior tectal membranes by temporal retinal axons. Development 101:909913.

Yip JW (1987) Target cues are not required for the guidance of sympathetic preganglionic axons. Brain Res 429:155-159. 